\title{
${ }_{226}$ Presidential Perspective
}

\section{From the Chair}

The Earth Sciences have made truly remarkable progress in the past decade. We now have a much better understanding of how the plates plunge into the mantle, and how this controls seismicity and volcanic activity at and near the Earth's surface. With astonishing precision we also know how fast climatic changes can occur, and we can describe the composition of the atmosphere for any period of time over the past 400,000 years. This knowledge provides excellent reference records for predicting future climatic change. At some locations we know so much about the subsurface, that, with the newly-found 'transparency' provided by techniques including GIS, our engineers can construct cheaper but more solid foundations for our highways. Regrettably, not much of this exciting new knowledge has yet caught the attention of our political leaders. In company with many members of the public, politicians and administrators tend to associate our science with a limited range of the more dramatic phenomena such as dinosaurs and spectacular, especially extra-terrestrial, catastrophes. It is not widely appreciated that such simplistic associations are a source of considerable loss and expense to human society. Billions of Euros and tens of thousands of lives are lost every year as a result of both civil action and inaction influenced by many misconceptions concerning the nature, magnitude and frequency of Earth processes. Until now, earth scientists have not had the platform from which to correct or advise upon, many situations of this kind. However, given the rapidly increasing impact of communications of all types (and at scales from the local to the global) that now characterize the modern world, it is considered that particular efforts should be made to bring to the attention of the people of the world and their leaders the nature and societal relevance of the Earth Sciences and their place in a sustainable future world.

From the very beginning of its term of office in 2000, the IUGS Executive Committee explored the idea for developing an International Year of Planet Earth, to be proclaimed jointly by the United Nations System and the IUGS. The very successful International Geophysical Year (IGY) in 1957 served as a stimulus and a model for this initiative. Within this framework, a primary aim "Year" must be to demonstrate the substantial and wide-ranging contribution the Earth Sciences can make towards ensuring a safer and more prosperous world. A feasibility study conducted in 2001 left no doubt that such an initiative can be successfully implemented. Now, at a point about halfway into the second phase of our preparations we are pleased to announce that the People's Republic of
China is prepared to formally propose to the UN system that an International Year of Planet Earth be declared. Of course, the nomination of this event as a "Year" is purely formal; it is self-evident that, if global reach is to be achieved, the magnitude of such a programme will require a three year period for its completion. Accordingly, we plan to make the

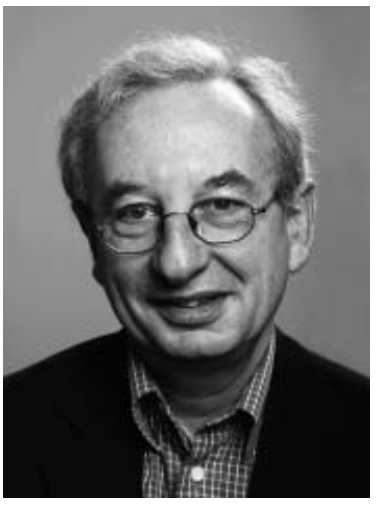
formal announcement of the inauguration of the programme at the International Geological Congress to be held in Florence (Italy) in August 2004. This will be followed up by the formal launch at a special conference in Beijing in February 2005, from which it will proceed into 2007, thereby commemorating IGY+50. A committee led by Prof. Edward Derbyshire is currently working on the Science Programme, which will deal with several major science topics, all with ambitious goals and societally-relevant goals. These topics will constitute the backbone and scientific essence in the 2005-2007 programme; they will all have a significant outreach component and a clear human dimensions. They will be of a global nature and actively involve the developing countries.

It goes without saying that the involvement and mutual cooperation of all geoscience bodies is vital to the sustained success of an initiative of this kind. Strong support for the "Year" has already been expressed by a number of key organizations but, of course, a great number of such bodies from around the world will be needed as partners and supporters in this initiative. It is for this reason that I now invite all geoscience organisations to express their interest in this major Earth Science venture. Please contact the Project Leader of the "Year", Dr. Henk Schalke at henkscha@worldonline.nl. He will gladly provide you with more information and help you to identify exactly what your organisation (or you as an individual) can do to advance the progression of this International "Year". Let us join forces and work together with resolution and focus for the benefit of both our Planet and our science!

\section{Eduardo F. J. de Mulder}

President, International Union of Geological Sciences 
